\title{
PENGARUH NASABAH DAN DEWAN PENGAWAS SYARIAH TERHADAP PENGUNGKAPAN LINGKUNGAN PERBANKAN SYARIAH INDONESIA
}

\author{
Zidni Husnia Fachrunnisal, Siti Afidatul Khotijah ${ }^{2}$ \\ ${ }^{1}$ Universitas PGRI Yogyakarta, zidnifachrunnisa@upy.ac.id \\ ${ }^{2}$ Universitas Tidar, khotijah_afi@untidar.ac.id
}

\begin{abstract}
ABSTRAK
Penelitian ini bertujuan untuk meneliti pengaruh nasabah dan Dewan Pengawas Syariah terhadap pengungkapan lingkungan pada bank syariah di Indonesia. Teori stakeholder manajerial digunakan sebagai teori utama untuk menjelaskan kerangka penelitian. Penelitian ini meneliti pengungkapan tanggung jawab sosial yang dipublikasikan pada laporan tahunan bank periode tahun 2016 sampai dengan tahun 2019. Penelitian ini menggunakan analisis isi pada item pengungkapan Islamic Social Reporting (ISR) dari penelitian sebelumnya. Data dianalisis menggunakan uji regresi berganda dengan WarpPLS versi 7.0. Hasil dari uji hipotesis, nasabah memiliki pengaruh terhadap pengungkapan lingkungan pada bank syariah di Indonesia, sedangkan Dewan Pengawas Syariah memiliki pengaruh negatif terhadap pengungkapan lingkungan pada bank syariah di Indonesia. Hal ini memberikan bukti empiris bahwa teori stakeholder manajerial sebagian mampu menggambarkan praktik pengungkapan lingkungan pada bank syariah di Indonesia. Implikasi dari penelitian ini yakni nasabah merupakan stakeholder kunci pada bank syariah sehingga dapat mempengaruhi luas pengungkapan terutama pengungkapan lingkungan pada bank syariah di Indonesia.
\end{abstract}

Kata Kunci : Nasabah, Dewan Pengawas Syariah, Teori Stakeholder Managerial, Pengungkapan Lingkungan.

\section{INTRODUCTION}

Masalah lingkungan akibat aktifitas bisnis menjadi isu menarik, berbagai masalah timbul seperti deforestasi, pemanasan global, hilangnya keanekaragaman hayati, gletser meleleh, erosi tanah, degradasi tanah, dan segala jenis polusi seperti air, udara, laut, kebisingan, cahaya dan lain sebagainya (Chandok, 2017). Bank yang merupakan institusi keuangan memainkan peran penting pada dampak lingkungan karena kebijakan pendanaan mereka atas bisnis yang didanai. Menurut (Kilic et al., 2015), bank memiliki tanggung jawab secara sosial maupun hukum karena bank membiayai sebuah entitas yang mungkin menghasilkan produk yang mencemari lingkungan.

Organisasi bisnis seharusnya tidak lagi dinilai sebagai entitas ekonomi saja, akan tetapi juga memiliki tanggung jawab atas sosial dan lingkungannya. Pada masa sekarang, Corporate Social Responsibility (CSR) atau tanggung jawab sosial perusahaan menjadi kunci utama untuk organisasi bisnis menjaga eksistensi dengan reputasi baik disamping mencapai laba maksimum (A. A. Rahman \& Bukair, 2013). Penelitian Pan, Sha, Zhang, \& Ke (2014) memberikan bukti 
bahwa CSR dapat membantu perusahaan untuk mengurangi biaya, sehingga laba perusahaan meningkat. Alasannya adalah bahwa industri yang secara signifikan mencemari polusi harus mengeluarkan banyak uang untuk mengurangi dampak lingkungan di bawah tekanan perhatian publik.

Orientasi perusahaan kini tidak hanya mencari profit, tetapi juga mulai memasukkan tujuan lain yakni meningkatkan kepedulian terhadap sosial dan lingkungannya. Di Indonesia, Kepedulian sosial mulai tampak nyata dengan adanya UU nomor 40 tahun 2007 yang mengatur tentang Perseroan Terbatas (Undang-Undang Republik Indonesia Nomor 40 Tahun 2007 Tentang Perseroan Terbatas, 2007) serta PP nomor 47 tahun 2012 (Peraturan Pemerintah Republik Indonesia Nomor 47 Tahun 2012 Tentang Tanggung Jawab Sosial Dan Lingkungan Perseroan Terbatas, 2012).

Praktik tanggung jawab sosial serta pengungkapannya sesuai dengan prinsip syariah yang mana Islam memiliki pandangan bahwa Akuntansi harus mencerminkan kondisi masyarakatnya serta membantu mencapai tujuan sosio-ekonomi masyarakatnya (Hameed \& Ibrahim, 2005). Dikatakan juga oleh Kamla, Gallhofer, \& Haslam, (2006), Prinsip-prinsip Islam merupakan cinta lingkungan dan manusia baik diri sendiri maupun orang lain, serta kesadaran akan pentingnya keseimbangan dan kebutuhan untuk mengambil tindakan yang beralasan untuk menjaga keseimbangan ini.

Perusahaan harus menyampaikan seluruh informasi terkait aktifitasnya untuk memenuhi tanggung jawabnya kepada stakeholders. Dalam akuntansi Islam konsep pertanggung jawaban yakni tanggung jawab terhadap Allah SWT serta tanggung jawab terhadap pemangku kepentingan termasuk masyarakat.

Kesesuaian prinsip Islam dengan pengungkapan CSR membuat anggapan bahwa orgnisasi bisnis Islam termasuk lembaga keuangan Islam mengungkapkan tanggung jawab sosialnya lebih transparan. Menurut Maali, Casson, \& Napier (2006) Bank syariah lebih bertanggung jawab atas pengungkapan sosial terlepas dari prinsip lokal karena mereka bertanggung jawab kepada masyarakat Islam. Namun, menurut A. Rahman, Cooper, \& Roberts (2013), rentan terjadi eksploitasi, dimana kekuatan stakeholder lemah dan seringkali kepentingan mereka diabaikan.

Menurut Darus, Mad, \& Nejati (2015), stakeholder primer seperti investor, nasabah, dan pemerintah dapat mempengaruhi bank untuk melakukan aktivitas CSR dan mengungkapkannya di laporan tahunan maupun laporan keberlanjutan. Penelitian Farook \& Lanis (2011) menunjukkan bahwa Investment Account Holder atau nasabah 
memiliki pengaruh terhadap pengungkapan CSR pada bank Islam. Selain itu, banyaknya Dewan Pengawas Syariah (DPS) akan melakukan pengawasan terkait kepatuhan lembaga keuangan Islam terhadap prinsip syariah dengan lebih baik, terutama dalam pengawasan aktivitas sosial bank serta pengungkapan Islamic Social Reporting bank (A. A. Rahman \& Bukair, 2013)

Penelitian ini memiliki tujuan untuk menguji apakah nasabah dan Dewan Pengawas Syariah mendorong bank syariah di Indonesia melakukan pengungkapan CSR pada aspek lingkungan. Penelitian sebelumnya yang meneliti pengungkapan lingkungan pada bank syariah yakni dilakukan oleh Darus et al. (2013) dengan sampel institusi Islam di Malaysia serta penelitian sebelumnya oleh Purwanti (2016) dan Fachrunnisa (2020). Penelitian ini mengambil sudut pandang yang berbeda yakni dengan perkspektif teori stakeholder manajerial yang menggunakan stakeholder kunci untuk menganalisa pengungkapan lingkungan pada bank syariah di Indonesia.

\section{LITERATURE REVIEW}

Teori stakeholder digunakan dalam menjelaskan hubungan diantara pemangku kepentingan seperti investor, kreditur, pelanggan, pemasok, karyawan, masyarakat dan pihak lainnya yang mendukung keberlangsungan perusahaan. Menurut
Deegan, Craig; Unerman (2011), teori stakeholder terdiri dari dua cabang yakni: manajerial dan etis. Pada teori stakeholder etis, semua stakeholder mempunyai hak untuk diperlakukan dengan adil oleh perusahaan. Semua stakeholder memiliki hak yang tidak boleh dilanggar. Sedangkan pada teori stakeholder manajerial, perusahaan lebih banyak mengeluarkan usaha untuk mengelola hubungan dengan stakeholder yang penting bagi perusahaan. Dalam teori ini, perusahaan akan memperhatikan stakeholder yang dianggap memiliki pengaruh penting bagi perusahaan agar mendapat dukungan dari mereka. Hal itu juga berlaku dalam pemberian informasi oleh perusahaan, dalam teori ini maka perusahaan hanya memberikan informasi kepada stakeholder tertentu. Melalui pengungkapan informasi kepada stakeholder kunci, perusahaan mengelola hubungan dengan stakeholder kunci sehingga perusahaan mendapatkan dukungan.

Teori stakeholder manajerial digunakan pada penelitian ini sebagai landasan teori untuk memprediksi hubungan nasabah dan DPS dengan tingkat pengungkapan lingkungan pada bank syariah di Indonesia. Pada teori ini, perusahaan menyampaikan informasi kepada stakeholder kunci sebagai upaya untuk memenuhi keinginan mereka mendapatkan dukungan dari mereka.

Manajemen bank merupakan agen dari pemegang saham dan juga mudharib sebagai 
nasabah atau pemegang Investment Account Holder (IAH) (Farook \& Lanis, 2011). Menurut Darus et al., (2015) pengaruh nasabah pada sebuah bank sangat penting karena nasabah memberikan dana untuk pendanaan bank tersebut. Dana dari nasabah menjadi sumber keuntungan bagi bank sehingga keuntungan pemegang saham juga ditentukan oleh keuntungan dari pemanfaat dana tersebut. Bank perlu untuk menjaga nasabah yang merupakan stakeholder kuncinya, sehingga, Bank Islam menginvestasikan dana IAH dalam kegiatan yang diperbolehkan syariah Farook \& Lanis (2011). Hasil dari penelitian Darus et al., (2015) menunjukkan bahwa nasabah adalah stakeholder yang memiliki kekuatan di lembaga keuangan yang dapat mempengaruhi aktifitas CSR dan berpengaruh terhadap peningkatan kualitas pengungkapan CSR. Selain itu, hasil penelitian Farook \& Lanis (2011) juga memberikan bukti bahwa IAH secara signifikan mempengaruhi pengungkapan CSR. Sehingga hipotesis penelitian ini adalah;

$\mathrm{H}_{1}$ :Nasabah memiliki pengaruh positif terhadap pengungkapan lingkungan pada Bank Syariah di Indonesia

Peran Dewan Pengawas Syariah (DPS) yakni sebagai pengawas kegiatan bisnis pada lembaga keuangan berprinsip Islam agar kegiatan bisnisnya berjalan sesuai dengan ketentuan dan prinsip syariah Islam. Terdapat kemungkinkan DPS berperan dalam mewajibkan kegiatan CSR dan juga mengungkapkannya (Farook \& Lanis, 2011).

Dewan Pengawas Syariah yang semakin banyak jumlahnya, maka dapat mengarahkan bank untuk mengungkapkan informasi lebih banyak termasuk pengungkapan CSR. Hal itu dikarenakan semakin banyaknya jumlah DPS, maka semakin tinggi tingkat pengawasan dalam penerapan prinsip syariah salah satunya pengungkapan aktivitas bisnis kepada stakeholder. Kaitannya dengan teori stakeholder manajerial, semakin banyaknya jumlah Dewan Pengawas Syariah yang mengawasi, maka bank berusaha untuk mematuhi prinsip syariah dengan mengungkapkan informasi CSR terutama pengungkapan lingkungan lebih banyak. Hasil penelitian A. A. Rahman \& Bukair (2013) dan Ramadhani (2016) memberikan bukti bahwa secara signifikan ukuran Dewan Pengawas Syariah memiliki pengaruh terhadap pengungkapan CSR. Selain itu, penelitian Purwanti (2016) juga memberikan hasil bahwa Dewan Pengawas Syariah berpengaruh terhadap pengungkapan aspek lingkungan, produk dan jasa pada bank Syariah. Banyaknya Dewan Pengawas Syariah memberikan pengaruh banyaknya pengungkapan terutama pengungkapan CSR. Dari penjelasan tersebut, dapat ditarik kesimpulan hipotesis dalam penelitian ini adalah; 
$\mathrm{H}_{2}$ : Dewan Pengawas Syariah memiliki pengaruh positif terhadap pengungkapan lingkungan pada Bank Syariah di Indonesia

\section{METHODS}

\section{Objek dan Sampel Penelitian}

Pada penelitian ini menggunakan objek penelitian yakni Bank Umum Syariah selama tahun 2016-2019. Penelitian ini memilih sampel dengan metode purposive sampling dimana menggunakan kriteria tertentu sebagai dasar pemilihan sampel. Adapun kriteria yang digunakan dalam pemilihan sampel pada penelitian ini yakni:

1. Bank Umum Syariah yang terdaftar di Otoritas Jasa Keuangan Tahun 2016 hingga 2019

2. Bank Umum Syariah yang mempublikasikan laporan tahunan atau annual report yang dapat diakses peneliti

3. Bank Umum Syariah yang mempublikasikan laporan tanggung jawab sosial pada laporan tahunan yang dapat diakses peneliti

\section{Analisis Data dan Pengujian Hipotesis}

Analisis statistik deskriptif digunakan sebagai analisis data dalam penelitian ini. Tujuannya untuk mengetahui karakteristik sampel dan gambaran variabel yang digunakan. Selanjutnya, Penelitian ini menggunakan uji goodness of fit inner model. Pengujian goodness of fit inner model digunakan untuk menguji apakah data yang diolah tidak mengandung bias. Setelah itu, dilakukan pengujian hipotesis.

Variabel dependen dalam penelitian ini yakni Pengungkapan Lingkungan. Sedangkan variabel independen yakni nasabah dan Dewan Pengawas Syariah. Model regresi berganda yang akan digunakan untuk menguji hipotesis yakni:

$\mathrm{PLB}=\alpha+\beta_{1} \mathrm{IAH}+\beta_{2} \mathrm{DPS}+\varepsilon$

Dimana,

$\alpha$

: Konstanta

$\beta_{1}-\beta_{2}$

: Koefisien

PLB

: Pengungkapan Lingkungan

IAH

: Investment Account Holder

DPS : Ukuran Dewan Pengawas Syariah

$\varepsilon$

: error term

Variabel dependen diukur menggunakan checklist item pengungkapan Islamic Social Reporting aspek lingkungan yang merupakan adopsi dari penelitian sebelumnya yakni penelitian Maali et al., (2006), Othman et al., (2009) dan A. A. Rahman \& Bukair (2013). Penelitian ini menganalisa ada tidaknya item pengungkapan pada laporan tahunan bank sampel, kemudian dibuat skoring. Sedangkan pengukuran variabel independen yang 
digunakan pada penelitian ini dijelaskan pada tabel berikut:

Tabel 1. Pengukuran Variabel Independen

\begin{tabular}{lll}
\hline Variabel & Metode & Referensi \\
\hline Nasabah & Presentase Dana & Darus (2015) \\
& Syirkah Temporer & \& Farook \\
& terhadap Total & $(2011)$ \\
& Ekuitas & \\
\hline Dewan & Jumlah Dewan & Rahman \\
pengawas & Pengawas Syariah & $(2013)$ \\
Syariah & & \\
\hline
\end{tabular}

\section{RESULTS AND DISCUSSIONS}

\section{Analisis Statistik Deskriptif}

Hasil analisis statistik deskriptif dari variabel dependen yakni pengungkapan lingkungan dapat ditunjukkan pada tabel 2 dibawah ini. Tabel 2 dapat menunjukkan bahwa minimum pengungkapan lingkungan yang diungkapkan oleh bank sampel yakni sebesar 0 atau dapat dikatakan terdapat bank sampel yang tidak mengungkapkan pengungkapan lingkungan pada laporan tahunannya. Nilai maksimum pengungkapan lingkungan pada bank sampel yakni sebesar 0,833 yang artinya, indeks tertinggi pengungkapan lingkungan pada bank sampel yakni 0,833 . Indeks tertinggi tersebut terdapat pada bank PT. Bank BRISyariah pada tahun 2018 dan PT. Bank BNISyariah pada tahun 2017. Sedangkan rata - rata skor pengungkapan lingkungan pada bank sampel yakni 0,333 dan standar deviasi yakni 0,219.

Tabel 2. Hasil Analisis Statisti Deskriptif Variabel Dependen

\begin{tabular}{cccccc}
\hline & $\mathrm{N}$ & Minimum & $\begin{array}{c}\text { Maksi } \\
\text { mum }\end{array}$ & Mean & $\begin{array}{c}\text { Std. } \\
\text { Dev }\end{array}$ \\
\hline $\begin{array}{c}\text { Pengungkapan } \\
\text { Lingkungan } \\
\text { (Indeks) }\end{array}$ & 44 & 0,000 & 0,833 & 0,333 & 0,219 \\
\hline
\end{tabular}

Sumber: Data Diolah (2021)

Gambar 1 dibawah ini menunjukkan perkembangan pengungkapan lingkungan pada setiap tahun pengamatan. Dapat dilihat pada gambar 1, indeks pengungkapan lingkungan tertinggi yakni pada tahun 2017 dan 2019 dengan nilai yang sama yakni 4 . Sedangkan indeks pengungkapan lingkungan terendah yakni pada tahun 2016 denagan nilai 3.

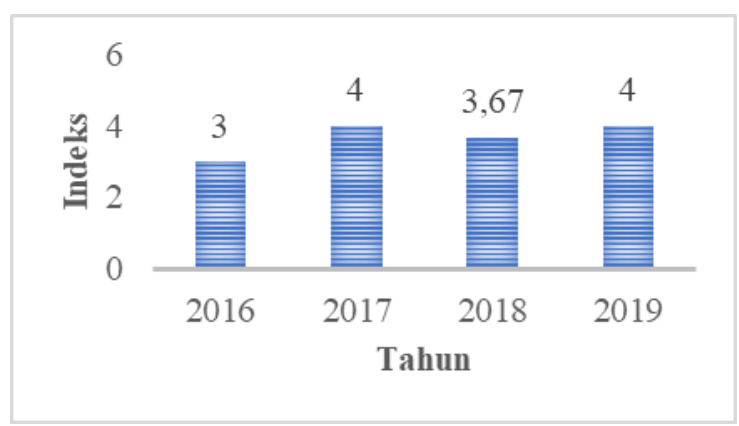

\section{Gambar 1. Grafik Pengungkapan Lingkungan}

Sumber: Data Diolah (2021)

Pada gambar 2 dapat dilihat grafik item pengungkapan lingkungan yang diungkapkan oleh bank sampel selama tahun pengamatan. Dari gambar 2 tersebut dapat dilihat bahwa item pengungkapan yang paling banyak 


\begin{abstract}
dilakukan yakni item pengungkapan konservasi energi dalam melaksanakan operasi bisnis. Sedangkan item pengungkapan terendah yang diungkapkan oleh bank sampel yakni pengungkapan tentang mendanai beberapa proyek yang mungkin menyebabkan kerusakan lingkungan.
\end{abstract}

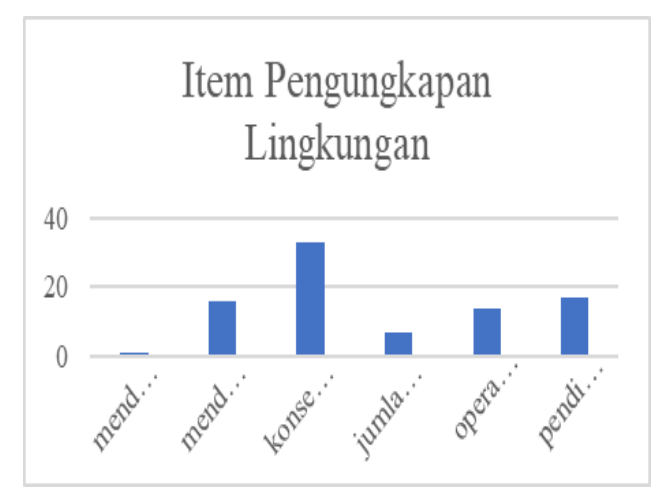

\section{Gambar 2. Grafik Item Pengungkapan Lingkungan}

Sumber: Data Diolah (2021)

Hasil analisis statistik deskriptif pada variabel independen dapat dilihat pada tabel 3. Variabel nasabah yang di proxy kan dengan Investment Account Holder memiliki nilai terendah yakni sebesar 71,1\% pada PT. Bank Aceh pada tahun 2016. Nilai tertinggi yakni sebesar 2808,59\% pada PT. Bank Panin Syariah, Tbk tahun 2017. Sedangkan nilai rata - rata yakni $621,6 \%$ dan deviasi standar yakni sebesar $440,2 \%$.

\section{Tabel 3. Hasil Analisis Statistik deskriptif Variabel Independen

\begin{tabular}{cccccc}
\hline & N & $\begin{array}{c}\text { Minim } \\
\text { um }\end{array}$ & $\begin{array}{c}\text { Maksi } \\
\text { mum }\end{array}$ & Mean & Std. Deviasi \\
& & & & & \\
\hline Nasabah (\%) & 44 & 71,1 & 2808,6 & 621,6 & 440,2 \\
& & & & & \\
\hline DPS (orang) & 44 & 2 & 3 & 2,27 & 0,451
\end{tabular}

Sumber: Data Diolah (2021)

\section{Uji Goodness of fit Inner Model}

Uji Goodness of fit Inner Model dilihat pada nilai R2. Pada penelitian ini, nilai R2 sebesar 0,220 atau $22 \%$, artinya variabel independen mampu menjelaskanvariabel dependen sebesar 22\%, sedangkan $78 \%$ dijelaskan oleh variabel lain diluar model penelitian. Selanjutnya, inner model atau model struktural apabila memiliki p-value pada ARS dan APC <5\% atau kurang dari 0,05 disebut sebagai model fit. Selain itu, nilai AVIF pada model fit yakni $\leq 5 \%$, idealnya $\leq 3,3$. Dapat dilihat pada tabel 4 , nilai ARS dan APC memenuhi kriteria inner model fit dengan nilai kurang dari 0,05 yakni sebesar 0,030 dan 0,001. Sedangkan nilai AVIF yakni sebesar 1,186. Sehingga, dapat diambil kesimpulan bahwa inner model pada penelitian ini telah lulus uji goodness of fit. 


\section{Tabel 4. Hasil Uji Goodness of Fit Inner Model}

\begin{tabular}{ccc}
\hline Hasil & Syarat & Kesimpulan \\
& & \\
\hline APC $=$ & p-value $<$ & Lulus \\
0,422 & 0,05 & \\
& & \\
p-value $=$ & & \\
0,001 & & \\
& & \\
ARS $=$ & p-value $<$ & Lulus \\
0,220 & 0,05 & \\
p-value $=$ & & \\
0,030 & & \\
& & \\
\hline AVIF $=$ & $\leq 5$, & Lulus \\
1,186 & ideally $\leq$ & \\
& 3,3 & \\
& & \\
\hline
\end{tabular}

Sumber: Data Diolah (2021)

\section{Hasil Uji Hipotesis}

Pengujian hipotesis pada penelitian ini menggunakan regresi berganda dengan WarpPLS 7.0 dengan tingkat signifikansi koefisien yakni p-value $\leq 0,05$. Sehingga apabila pada hasil pengujian memiliki nilai $\mathrm{p}$ value kurang dari 0,05 ( $\mathrm{p}$-value $\leq 0,05$ ), maka dapat diartikan bahwa variabel independen berpengaruh signifikan terhadap variabel dependen. Sebaliknya, apabila hasil pengujian memiliki nilai $\mathrm{p}$-value lebih dari 0,05 (p-value $>0,05)$, maka dapat diartikan bahwa variabel independen tidak berpengaruh signifikan terhadap variabel dependen. Berikut hasil pengujian hipotesis pada penelitian ini:

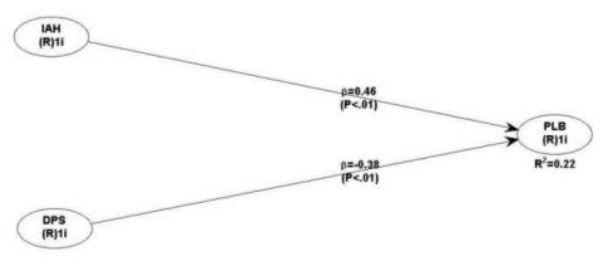

\section{Gambar 3. Hasil Uji Hipotesis dengan WarpPLS 7.0}

Sumber: Data Diolah, 2021

Pada gambar 3 diatas, dapat dilihat IAH atau variabel nasabah memiliki p-value sebesar 0,01 atau kurang dari tingkat signifikansi 0,05. Artinya, variabel nasabah berpengaruh signifikan terhadap variabel dependen. Variabel nasabah memiliki nilai koefisien jalur $(\beta)$ yakni sebesar 0,46, sehingga variabel nasabah mempengaruhi variabel dependen dengan arah positif. Dari hasil tersebut, dapat diartikan bahwa variabel nasabah berpengaruh positif terhadap pengungkapan lingkungan. Sedangkan variabel DPS memiliki nilai $\mathrm{p}$-value sebesar 0,01 kurang dari tingkat signifikansi 0,05. Artinya, variabel DPS berpengaruh signifikan terhadap variabel dependen. Nilai koefisien jalur ( $\beta$ ) pada variabel Dewan Pengawas Syariah sebesar $-0,38$, artinya variabel DPS berpengaruh pada variabel dependen dengan arah negatif. Sehingga, dapat diartikan bahwa variabel DPS memiliki pengaruh negatif terhadap pengungkapan lingkungan.

Dengan hasil tersebut, maka hipotesis 1 (H1) dalam penelitian ini yang menyatakan 
bahwa nasabah memiliki pengaruh yang positif terhadap pengungkapan lingkungan pada bank syariah di Indonesia diterima. Hasil penelitian ini mendukung hasil penelitian dari Farook \& Lanis (2011) yang menunjukkan bahwa nasabah memiliki pengaruh terhadap pengungkapan tanggung jawab sosial pada bank Islam. Selain itu juga hasil penelitian Darus et al., (2015) menujukkan bahwa nasabah berpengaruh terhadap peningkatan kualitas pengungkapan CSR pada lembaga keuangan. Hal ini sesuai dengan teori stakeholder manajerial yang menyatakan bahwa semakin kuat peran stakeholder bagi perusahaan maka perusahaan semakin berusaha untuk mengelola hubungan baik dengan stakeholder tersebut. Sehingga, semakin besar porsi dana nasabah akan membuat bank lebih banyak membuat pengungkapan CSR terutama pengungkapan lingkungan pada laporan tahunannya.

Selanjutnya, Hipotesis 2 (H2) pada penelitian ini yang menyatakan bahwa Dewan Pengawas Syariah memiliki pengaruh positif terhadap pengungkapan lingkungan pada Bank Syariah di Indonesia ditolak. Hasil dari uji hipotesis dalam penelitian ini, DPS memiliki pengaruh negatif terhadap pengungkapan lingkungan pada bank syariah di Indonesia. Hasil ini tidak sesuai dengan hasil penelitian Ramadhani (2016) dan A. A. Rahman \& Bukair (2013) bahwa semakin banyak jumlah DPS pada suatu perusahaan dapat meningkatkan tingkat pengungkapan CSR. Pada penelitian ini, DPS berpengaruh negatif terhadap pengungkapan lingkungan, artinya semakin banyak DPS pada suatu bank, maka pengungkapan lingkungan semakin sedikit. Hal ini karena kemungkin adanya faktor lain yang mempengaruhi pengawasan oleh Dewan Pengawas Syariah pada suatu bank seperti rangkap jabatan, lama jabatan, independensi, kompetensi, kehadiran dan keaktifan (Baehaqi, 2014). Dimungkinkan dengan banyaknya DPS pada suatu bank semakin jelas tugas masing - masing anggota DPS karena adanya delegasi penugasan pengawasan, sehingga mengurangi adanya frekuensi rapat. Menurut Purwanti (2016) pengawasan DPS akan lebih efektif jika DPS sering melakukan koordinasi. Kurangnya frekuensi rapat mungkin mengurangi efektifitas pengawasan DPS terhadap penerapan prinsip syariah pada suatu bank dan dapat mempengaruhi judgment DPS terhadap penerapan prinsip syariah pada suatu bank. Sehingga membuat bank mungkin kurang berupaya memenuhi keinginan semua Dewan Pengawas Syariah yang dimiliki.

\section{CONCLUSION}

Kesimpulan dari penelitian ini yakni hipotesis (H1) yang menyatakan bahwa nasabah memiliki pengaruh positif terhadap tingkat pengungkapan lingkungan pada Bank Syariah di Indonesia dapat diterima. Hal ini 
sesuai dengan teori stakeholder manajerial yang beranggapan bahwa semakin penting peran stakeholder bagi perusahaan maka perusahaan semakin mengeluarkan banyak usaha untuk mengelola hubungan dengan stakeholder tersebut. Selanjutnya, Hipotesis 2 (H2) pada penelitian ini yang menyatakan bahwa DPS memiliki pengaruh positif terhadap pengungkapan lingkungan pada Bank Syariah di Indonesia ditolak. Dari hasil uji hipotesis dalam penelitian ini, Dewan Pengawas Syariah memiliki pengaruh negatif terhadap tingkat pengungkapan lingkungan pada Bank Syariah di Indonesia. Hal ini dimungkinkan karena dengan banyaknya DPS pada suatu bank semakin jelas tugas masing masing anggota DPS karena adanya delegasi penugasan pengawasan, sehingga mengurangi adanya frekuensi rapat. Kurangnya frekuensi rapat mungkin mengurangi efektifitas pengawasan DPS terhadap penerapan prinsip syariah pada suatu bank, sehingga dapat mengurangi judgment DPS terhadap penerapan prinsip syariah pada suatu bank. Hal itu mungkin membuat bank kurang berupaya memenuhi keinginan semua Dewan Pengawas Syariah yang dimiliki.

Penelitian ini memberikan implikasi bahwa teori stakeholder manajerial sebagian mampu menggambarkan praktik pengungkapan lingkungan pada bank syariah di Indonesia. Nasabah merupakan stakeholder kunci pada bank syariah di Indonesia sehingga dapat mempengaruhi luas pengungkapan terutama pengungkapan lingkungan. Semakin besarnya kekuatan nasabah yang diproxykan dengan besarnya prosentase dana nasabah (Investment Account Holder), maka semakin kuat pengaruh nasabah terhadap bank dalam mengungkapkan tanggung jawab sosialnya terutama aspek lingkungan.

Penelitian ini hanya menggunakan variabel nasabah dan Dewan Pengawas Syariah, kemudian penelitian ini hanya menggunakan media laporan tahunan yang diterbitkan untuk meneliti pengungkapan lingkungan pada bank syariah di Indonesia. Saran dari penelitian ini yakni komponen lain dalam Islamic Corporate Governance dapat ditambahkan sebagai pengukuran pengaruh Dewan Pengawas Syariah terhadap pengungkapan lingkungan. Kemudian, penelitian berikutnya dapat menambahkan variabel lain kaitannya dengan stakeholder kunci yang tidak digunakan dalam penelitian ini. Media pelaporan lain seperti website atau laporan keberlajutan bank juga dapat digunakan sebagai media tambahan.

\section{REFERENCES}

Baehaqi, A. 2014. Usulan Model Sistem Pengawasan Syariah Pada Perbankan Syariah Di indonesia. Jurnal Dinamika Akuntansi Dan Bisnis, 1(2), 119-133. https://doi.org/10.24815/jdab.v1i2.3583

Chandok, R. I. S. 2017. Empirical Study on 
Determinants of Environmental Disclosure: Approach of Selected Conglomerates. Managerial Auditing Journal, 32(4/5).

Darus, F., Mad, S., \& Nejati, M. 2015. Ethical and Social Responsibility of Financial Institutions: Influence of Internal and External Pressure. Procedia Economics and Finance, 28(April), 183-189. https://doi.org/10.1016/S22125671(15)01099-0

Darus, F., Yusoff, H., \& Mohd Azhari, N. K. 2013. Environmental Disclosure of Islamic Financial Institutions (IFIs): Preliminary Evidence from Malaysia. Journal of Energy ..., 3(11), 433-439. http://search.ebscohost.com/login.aspx? direct $=$ true $\&$ profile $=$ ehost $\&$ scope $=$ site \&authtype $=$ crawler $\&$ jrnl $=22250573 \& A$ $\mathrm{N}=93478004 \& \mathrm{~h}=\mathrm{VC6TTj7DLH}+$ nlhyq MkHRDVg0t7gDI5qw+m9SujYa1QY0 mu3KMXpJCPVDv5Lc2OSam8/NMU 3 vwfF8mSZwohvQJQ==\&crl $=\mathrm{c}$

Deegan, Craig; Unerman, J. 2011. Financial Accounting Theory. Mc Graw - Hill.

Fachrunnisa, Z. H. 2020. Pengungkapan Lingkungan Pada Bank Syariah Di Indonesia. Jurnal Riset Akuntansi, 5(1), $32-45$.

Farook, S., \& Lanis, R. 2011. Determinants of corporate social responsibility disclosure: the case of Islamic banks. 114-141. https://doi.org/10.1108/1759081111117 0539

Hameed, S., \& Ibrahim, M. 2005. The emerging issues on the objectives and characteristics of islamic accounting for Islamic business organizations. Malaysian Accounting Review, 4(1), 75-92.

Pemerintah Indonesia. 2012. Peraturan Pemerintah Republik Indonesia Nomor
47 Tahun 2012 Tentang Tanggung Jawab Sosial Dan Lingkungan Perseroan Terbatas.

Pemerintah Indonesia. 2007. Undang-Undang Republik Indonesia Nomor 40 Tahun 2007 Tentang Perseroan Terbatas.

Kamla, R., Gallhofer, S., \& Haslam, J. 2006. Islam, nature and accounting: Islamic principles and the notion of accounting for the environment. 30, 245-265. https://doi.org/10.1016/j.accfor.2006.05. 003

Kilic, M., Kuzey, C., \& Uyar, A. 2015. The Impact of Ownership and Board Structure on Corporate Social Responsibility ( CSR ) Reporting in the Turkish .... Corporate Governance, 15(November), 357-374. https://doi.org/10.1108/CG-02-20140022

Maali, B., Casson, P., \& Napier, C. 2006. Social Reporting by Islamic Banks. 42(2). https://doi.org/10.1111/j.14684497.2006.00200.x

Othman, R. 2009. Determinants of Islamic Social Reporting Among Top Shari' aApproved Companies in Bursa Determinants of Islamic Social Reporting Among Top Shariah Approved Companies in Bursa Malaysia. Research Journal of International Studies, January.

Pan, X., Sha, J., Zhang, H., \& Ke, W. 2014. Relationship between Corporate Social Responsibility and Financial Performance in the Mineral Industry: Evidence from Chinese Mineral Firms. 4077-4101. https://doi.org/10.3390/su6074077

Purwanti, A. 2016. Dewan Pengawas Syariah Dan Pengungkapan Aspek Lingkungan, Produk Dan Jasa Pada Bank Syariah. Jurnal Akuntansi Dan Keuangan Islam, 
4(2), 169-182.

Rahman, A. A., \& Bukair, A. A. 2013. The Influence of the Shariah Supervision Board on Corporate Social Responsibility Disclosure by Islamic Banks of Gulf Co-Operation Council Countries. 6(2), 65-104.

Rahman, A., Cooper, S. M., \& Roberts, R. W. 2013. Vulnerable and exploitable: The need for organisational accountability and transparency in emerging and less developed economies. Accounting Forum, $\quad 37(2), \quad 81-91$. https://doi.org/10.1016/j.accfor.2013.04. 001
Ramadhani, F. 2016. Pengaruh Ukuran Perusahaan, Profitabilitas, Leverage Dan Ukuran Dewan Pengawas Syariah Terhadap Pengungkapan Islamic Social Reporting (Studi Empiris Pada Bank Umum Syariah di Indonesia Tahun 2010-2014). JOM Fekon, 3(1), 24872500 . 